\title{
The Perception of English Consonants by Arab ELF Learners. A Case Study of University Students at ZU.
}

\author{
Jamal Azmi Salim \\ Department of English \\ Zarqa University, Jordan \\ Mohammed A. Al-Badawi \\ Department of English \\ Zarqa University, Jordan
}

This research is funded by the Deanship of Scientific Research at Zarqa University

\begin{abstract}
The present research focuses on the perception of English consonant sounds by the learners of English at university level. English and Arabic, genetically two different languages, share some common features. They also exhibit a lot of differences. These differences are the main source of difficulty in the learning of English as a foreign language and vice-versa. Some Arabic speakers perform oddly on a range of experimental tasks which involve word discrimination. All these tasks involve discriminating words with identical vowel patterns, but differing in their consonants. Some Arabic learners, it seems, are consciously inaccurate in handling consonants in English words, and much more prone to make errors involving consonants than subjects of other mother tongue background. One possible explanation to these errors is that Arabic speakers seem to transfer to English a set of psycholinguistic strategies that are more appropriately deployed in processing Arabic words. Unlike English, Arabic vowels are of secondary importance both in script and in word building, and the word recognition system depends heavily on the tri-consonantal roots which are the basis of most Arabic words with vowel variations placed within the consonantal framework. From a pedagogical point of view, such differences between the two languages will be determined and included in the various teaching material. In other words, teaching will be directed on these differences. This in turn determines what the teacher has to teach and what the learner has to learn. The present researchers anticipate that the similarities between the two systems would act as a reference point for the learner's perception of the English consonants. The results of the present paper would in turn encourage instructors to follow similar procedures in their teaching of sounds at university level in particular.
\end{abstract}

Key words: English as a foreign language (EFL), Modern Standard Arabic (MSA), Zarqa University (ZU).

\section{INTRODUCTION}

English and Arabic, genetically two different languages, share some common features. They also exhibit a lot of differences. These differences are the main source of difficulty in the learning of English as a foreign language and vice-versa. It is observed that one of the major problems in the learning of a foreign language is the interference caused by the differences between the native language and the second language. When a child acquires his native language, he develops his native language behaviour which gradually becomes internalized. However, in learning a foreign language, the learner is very much influenced by his native language behaviour. Where the structure of the two languages is the same, no difficulty is 
anticipated. Where the structure of the second language (L2) differs from (L1), we can predict both difficulty in learning and error in performance. The bigger the differences between the two languages, the greater the difficulty will be. Thus, it is important in learning a foreign language to overcome these difficulties. In other words, learning a foreign language means learning to change one's native language behaviour to that of the speaker of the target language.

Perez (2005) claims that in the phenomenon categorical perception; is the process of labelling that limits our perception of sounds. In such cases listeners break words down to their phonemic categories in the listener's language, and ignore the unessential variations within a category i.e categorical perception within sound system of the first language hinders the perception of new words (unessential) variations of the second language. However, Emas (1975) argues that the infants can group speech stimuli in phonetic categories soon after birth, and they do not have to learn them when they acquire their native language. Streeter (1976) further explains that infants are able to perceive most but not all sounds that are not used in their native language. So, if this is the case in the first language acquisition, why are not the adult EFL learners able to perceive sounds that are nonexistent in their native language? Wreker (1939) conducted a study on the change of speech perception during development. The test was applied to different age groups eight months, four years, eight years, twelve years and adults. The study confirmed that the decline in the universal phonetic sensitivity begins at the age of six months onwards. Wreker (1939) further argues that it is difficult to regain phonetic sensitivity in adulthood and there normally would be a lack of ability to differentiate between phonetic contrast.

More recent studies however (Bradlow and Pisoni, 1997, Rochet, 1995), have tackled training adults to perceive and discriminate new phonetic contrast that are nonexistent in their native language. The results show that with training, there is a chance for improvement, but most studies have focused on training EFL learners to differentiate consonant sounds, and there is little research that has been conducted on perception of vowels especially in Arabic.

One of the pioneers in training adult learners in the perception of new sounds in FL is Brown (1995) who argued that training with minimal pairs was not as useful as training with suprasegmentals, but no evidence was provided for such claim. To contend this claim Perlmutter (1989) carried on a study on ESL learners who were given language instruction with special emphasis on pronunciation. The results of the study reflected an improvement in the students' perception of new speech sounds specific to the second language. Dewing, Munro and Wiebe (1998) have shown that a twelve weeks course of intensive training can improve second language learners; ability in realizing the phonetic contrasts that are nonexistent in their native language. Although the above mentioned studies emphasize that suprasegmentals pronunciation aspect, it would be interesting to conduct studies using suprasegmentals and minimal pairs and find out about their results.

The present study is rather a continuation of a paper previously carried out by the same authors entitled "perception of English vowels", focuses on the perception of English consonant sounds by EFL learners of English at university level. The aim of this study is pedagogical. When EFL learners are exposed to a set of consonant sounds that are not present in their own language, they will typically not perceive this set of sounds as an English native speaker's perception. From a theoretical point of view, the present researchers anticipate that the similarities between the two systems would act as a reference point for the learner's perception of the English consonants. 
Carter, Nunan (2001), and O'Connor (2003) noted that the pronunciation mistakes made by learners of English as a foreign language are systematic and they fall into a certain pattern where learners for instance replace $/ \mathrm{p} /$ sound with $/ \mathrm{b} /$ and $/ \theta$ / with /s/. Linguistically speaking, there are certain factors that might influence learners' problems in the pronunciation of English. Among these factors is the mother tongue interference; Brown (2000) states that EFL learners have difficulty in pronunciation because of the influence of L1 over L2 especially in their adulthood. Yule, O'Connor (2003) claimed that the main challenge would meet the EFL learners is to build a new set of sounds in opposition to their L1 set of sounds and to break down the arrangements of sounds which have been internalised (fossilised) in their phonological system.

Another potential source of pronunciation problems is the in discrepancy between the orthography and the pronunciation of English where the spelling of some English words might lead EFL learners to guess the wrong pronunciation unless they establish a good knowledge of the relationships that exist between English sounds and letters. O'Connor (2003) cites some examples of homographs (words with the same spelling and different pronunciation) such as 'read' pronounced as /red / instead of /ri:d/ and 'lead' that is pronounced as /led/ instead of /li:d/. In addition to homophones (words with the same pronunciation and different spelling) such as 'rain', 'reign' and 'rein' are pronounced as /rein/. "Waste' and 'waist' pronounced as /weist/.

Many researchers and linguists such as Carter, Nunan (2001), and O'Connor (2003) concluded the problems that EFL learners face at a pronunciation level are similar in nature but sensitive to the EFL Learners' first language. Arab learners of English and Jordanian Arab learners of English in particular are no exception in that sense. This paper comes as an attempt to validate further findings in this field. Thus, it is the purpose of this paper to investigate the consonants' pronunciation problems committed by students majoring in English language at Zarqa University, Jordan.

To achieve this goal the paper will proceed with some description of the English consonants, then it will clarify the methodology adopted by the present researchers. A discussion of the problems will follow according the proposed groups of consonants. Then it will end with conclusions mentioning some limitations of this study.

\section{ENGLISH CONSONANTS}

Speech sounds are generally divided into vowels and consonants. The main difference between them according to Ward (1971: 65) is one of sonority: vowels are sounds which carry power. In ordinary speech, a vowel is a voiced sound in the pronunciation of which the air passes through the mouth in a continuous stream, there being no obstruction. A consonant, on the other hand, is a sound, produced with a stoppage (complete or partial) of the breath, that is to say, in the production of a consonant the movement of the air from the lungs is obstructed as a result of narrowing or a complete closure of the air passage. In some other words, "A consonant sound is formed when the air stream is restricted or stopped at some point between the vocal cords and the lips" (Todd: 1987:14).

The word consonant has been derived from Greek word consonantem which means the sound produced with the help of some other sounds (vowels). Both the ancient Greeks and Indians define the consonant as a sound produced with the , monosyllabic, as in the word 'lord', disyllabic as in the word 'lordship', tri-syllabic as in the word 'tenderly', tetra-syllabic, as in the word ' invocation', penta-syllabic, as in the word 'invulnerable' and hetra-syllabic, as in the word 'unhesitatingly', and hepta-syllabic as in the word' invulnerability'. In some other words, 
the description of a consonant sound requires the following criteria: nature of the airstream mechanism, the state of the glottis, the position of the velum, the articulators involved and the nature of the stricture (manner of articulation).

The BBC English (Received Pronunciation) is the accent that is most often recommended for foreign language learners studying British English and has always been chosen by teachers, and the accent that has been most fully described and has been used as the basis for pronouncing dictionaries (Roach:2000). The British English consonant system comprises twenty four consonantal phonemes. They are as follows:

\section{Plosives}

English has six plosives: / p, t, k, b, d, g /.The voiceless plosives are aspirated in the word initial position. / b, d, g / cannot be preceded by any consonants, in the initial position, but / p, t, k / may be preceded by a voiceless alveolar fricative /s/, as in / sp a: k, stri:t, skwi:z / . In this case they become unaspirated. While in the word final position voiced stops become devoiced, and the vowels preceding / p, t, k / are much shorter ( Roach: 2000).

\section{Fricatives}

English has nine fricatives / f, v, s, z, $\theta$, ð, $\int, 3, \mathrm{~h} /$. The voiced fricatives can be devoiced in the word final position.( yarmohammadi: 1996). The fortis fricatives have the effect of shortening the preceding vowel, as do fortis plosives. The sound / $3 /$ is of limited occurrence, and $/ \mathrm{h} / \mathrm{has}$ the quality of the vowel that follows it. The same kind of difference in vowel length occurs before voiceless and voiced fricatives. The vowel is shorter in the first word of each of the pairs "strife, strive"; "teeth, teethe"; " rice, rise"; and "mission, vision" ( Ladefoged, 2001: 51).

\section{Affricates}

Affricates are produced with a constriction of complete closure followed by a release phase in which friction occurs. One of the main differences between the first sound in "tip" and the first sound in "chip" is that, during the release phase of the /t/ in 'tip', there is no friction of the sort one finds during the release phase of the first sound in 'chip'. We might therefore think of affricates as a sequence of a stop followed by a homorganic fricative (Carr, 2013: 12-13). The two affricates / $\mathrm{t} \int$ and $\mathrm{d} 3 /$ occurs in the speech of most speakers of English. The sound / $\mathrm{t} \int /$ is frequently found in colloquial Arabic but not in standard Arabic.

\section{Nasals}

English has three nasals /m, n, $\mathrm{y} /$. Whereas Arabic has only two nasals /m, and $\mathrm{n} /$.The sound /ng/ is not regarded as a phoneme in Arabic (Nasr, 1967:26). In English, It never occurs in initial position or after a diphthong or a long vowel (Roach, 2000).

\section{Lateral}

English has only one lateral /l/. In BBC pronunciation, the realisation of /l/ in the word 'lea' /li:/ is quite different from that of 'eel' /i:l/. The sound in /li:/ is what is called a 'dark l' it has a quality rather similar to a /u/ vowel, with the back of the tongue raised. The sound in /li:/ is what is called a 'clear l' ; it resembles an /i/ vowel, with the front of the tongue raised. The dark /l/ never occurs before vowels and the clear /l/ will never occur before consonants but only before vowels (Roach, 2000:61)

\section{Approximants}

English has three voiced approximants/ w, r, j /. The articulation of each of them varies slightly depending on the articulation of the following vowel: / raw, reap, we, water, lee, law, yet and 
yaw/. These consonants also share the possibility of occurring in consonant clusters with stop consonants (ladefoged, 2001: 54-55).

\section{METHODOLOGY}

Thirty-six native speakers of Arabic, ranging between 17 and 25 years of age, and at second and third year university level took part in the study. All of the participants are from Jordan and they are all classified as foreign language learners. They were also enrolled in a Listening and Speaking course - a first year course for students majoring in English Language and Literature and translation. The students were split randomly into two groups - an experimental group and a control group. Each group consisted of 18 students, and all participants had a positive attitude towards the training process.

No specific pronunciation instruction was provided for the control group, while the experimental group was provided with 50 minutes of pronunciation classes, three times a week for four weeks. The students in both groups attended 48 hours of language classes per semester, the courses run over a period of 16 weeks three times a week which emphasized pronunciation. Students in the experimental group were introduced to the vowel systems in English and Arabic, and their progress was evaluated by a quiz at the end of the instruction stage. No recordings were used in the training.

30 different words were given to the subjects. These words were recorded by a British native speaker and were grouped into five groups according to the consonant contrast as follows:

Group one : /p/ and /b/

Group two: $/ \mathrm{t} \int /$ and $/ \mathrm{s} /$

Group three: $/ \mathrm{d} 3 /$ and $/ 3 /$

In the pre-test stage the subjects were asked to pronounce the minimal pairs in the five groups. It is worth mentioning that such sounds namely, $\mathrm{t} \int, 3, \mathrm{~g}$, are found in colloquial Arabic. Whereas, /p and v/ do not exist in Arabic, therefore, the problem for students was a matter of perception.

\section{Substitution}

\section{RESEARCH HYPOTHESIS}

It is hypothesized that if students are aware of the proper pronunciation at their competence level, but due to their poor performance in articulation, they would normally substitute the phoneme in question (which normally doesn't exist in their L1 phonological system) with the closest similar phoneme, for example, the voiceless /p/ sound doesn't exist in standard and colloquial Arabic, thus it is normally substituted with the voiced /b/.

\section{Overgeneralization}

In other cases, certain patterns of pronunciation are over generalized once they are learnt in L2.For example, the past participle /-ed/ form is learnt in words like 'started' /sta:rtid/. It is normally carried over in similar situations even when it is pronounced differently as in the case of /d/ in /trævld/ and /t/ in / a: skt/.

\section{Group one: /p/ and /b/}

\section{DISCUSSION AND RESULTS}

The voiced bilabial stop phoneme /b/ is found in Arabic while /p/ does not exist. These two sounds are separate phonemes in English. The present researchers observed two behaviours among subjects for the phonemes $/ \mathrm{p} /$ and /b/. The first behaviour is generally noticed among male students where they tend to substitute the phoneme /p/ with /b/ because it is the closest 
existent phoneme in L1 phonological system. Such substitution leads to different meanings e.g. 'big' and 'pig', 'pray and bray', 'park and bark'. The second behaviour is noticed among female students who learn the new phoneme /p/, but they normally tend to over generalize it in the place of the /b/ phoneme. For example, they would mispronounce words like' but, bus, bye,' for ' putt, puss, pie'. It has also been observed that students substitute the aspirated /p/ by the voiced /b/ in words as, park, pray. This kind of substitution does result in the change of meaning. Moreover, students might get used to a certain way of pronouncing a certain sound either because of faulty teaching or because they seem stuck in the journey between L1 and L2. Such "Inter-language" errors (Yule, 2009) might be the cause of a previous language teacher who mispronounced some sounds and is taken as a model for correct pronunciation. Alternatively, as the learner sets his inter-language journey, he might get stuck with fossilised errors and with little improvements to take record of.

\section{Group two: /t $\mathrm{t} /$ and $/ \mathrm{J} /$}

There was a problem of pronouncing $/ \int$ and $\mathbf{t} \int /$, even though, they both exist in the phonological repertoire of the students. Because at the performance level (articulatory), Jordanian students come from three social backgrounds where the distribution of these two phonemes is different, For example,/ $\mathbb{\int}$ / exists in the three varieties, namely, Madani, Falahi and Badawi. However, / $\mathbf{I} /$ does only exist in Badawi and Fallahi but not in Madani. Moreover, the present researchers believe that at the social variable of the sex has to do with distribution of the phoneme / t $\int$ / in the Arabic Jordanian varieties. Down that line normally female speakers of both Fallahi and Badawi Jordanian Arabic tend to adopt the Madani variety which is conventionally more prestigious.

Thus students in the control group have more tendency to substitute the /ts/ phoneme with / $\int$ / phoneme from L1. So, there was a higher frequency of mistakes among them in words like/ children, charity, watching, merchant, witch, choose, challenge, furniture, teacher / due to the same reason. In some other words, the majority of students in the control group usually perform substitution of the phoneme $/ \int /$ for $/ \mathbf{t} \int /$ and vice versa. For example, $75 \%$ the word 'children' has been pronounced as / $\int$ ildren/ the word 'watching' as /w $\mathrm{p} \int \mathrm{ing} /$. 'Choose' has also been pronounced as / $\int \mathrm{u}: \mathrm{z} /$. 'Which' has been pronounced as /wi $\int /$ merchant as /mer $\int$ ant/ chopping as /shopping. Charity as $/ \int$ arity/. The replacement of $/ \int /$ by $/ \mathbf{t} \int /$ does also result in the change of the meaning of such words.

\section{Group three: / d 3 / and / 3 /}

It has been observed that the majority of students are likely to commit a lot of mistakes when pronouncing the phoneme / 3 / in words "measure, treasure, pleasure, leisure, vision, compulsion". Thus students in the control group have more tendency to substitute the /3/ phoneme with / $\mathrm{d}_{3}$ / phoneme from L1. So poor production of this sound is very noticeable. As a matter of fact, the / 3 / sound is not found in MSA, it does exist in colloquial variety.

In order to measure the effect of training on students, they were given a pre-test and a posttest design. During the pre-test both the control and the experimental groups were first given a printed material and made to listen to the recorded stimuli, which was played only once. Then they had to identify and circle the word they heard in the recording. Whereas in the post-test the experimental group attended 50 minute pronunciation sessions three times a week for four weeks, then students from both groups were again tested using the same method as the pretest.

Students in the control group did not do as well in the post-test as they did in the pre-test, scoring a mean percentage of $56 \%$ before taking the classes, and $53 \%$ after. The experimental 
group however did considerably better. The mean percentage of their scores in the pre-test was $62 \%$ which increased to $80 \%$ in the post-test.

The following results were arrived at upon analysis of the individual pairs of consonants: First, the control group showed a slight improvement in their recognition of the contrasting pairs of $/ \mathrm{p} / \mathrm{-} / \mathrm{b} /$. While their pre-test scores were $50 \%$, their post-test scores went up to $59 \%$. The experimental group however showed a significant improvement, with their post-test scores jumping 30\% from their pre-test scores. Pre-training the group managed a score of 55\% and after four weeks of training, their test scores went up to $88 \%$, showing that the instructions and the practice given on differentiating between $/ \mathrm{p} /$ and $/ \mathrm{b} /$ helped them considerably.

The analysis of the second group contrasting pair of consonants / $\mathbf{t} \int$ / and $/ \boldsymbol{\int} /$ showed a slight drop in the control group's scores, going from $46.6 \%$ in the pre-test to $38 \%$ in the post-test. There is no obvious explanation as to why this has happened. However, the experimental group showed they had benefited from the training and explanation given during class in order to differentiate between / t $\int /$ and / $/$ / Their pre-test scores were $46.6 \%$ and went up to $68.8 \%$ in the post -test.

The third and the final pair of consonants /d3/ and /3/ proved somewhat easier to recognize for the control group. Without the training the experimental group received, the control group's post-test scores increased by 5\%, going up from $55.5 \%$ in the pre-test to $61.1 \%$ in the post-test. Meanwhile, the experimental group achieved much higher results due to the training they were granted. Their recognition of the contrasting pair of consonants went up from $61.1 \%$ in the pre-test to $83.3 \%$ in the post-test.

\section{CONCLUSIONS}

The discussion results above revealed that training adult learners to perceive new sounds in the FL show that the perception of new consonant sounds can be achieved not only theoretically but also practically. This would in turn encourage teachers and instructors to follow similar procedures in their teaching of new sounds at Zarqa University in particular. Finally, the researchers hope the present research may stimulate other researchers to start where this paper ends, and do extensive academic work focused on phonology. If this paper manages to do so, it has, then, and only then, achieved its own objectives.

It might be suggested that when teaching the sound system of English, the focus should be made on such problematic sounds differences. Teachers should recognize the pronunciation errors and expose students to the correct pronunciation through extensive drills and exercises. Students are also suggested to expose their ears to as much spoken English as possible. It is strongly recommended at the end of this study to increase the number of courses at Zarqa University that incorporate pronunciation exercises and not limit this to one course in phonetics and another in listening and speaking.

\section{LIMITATION OF THE STUDY}

The study carried out is based on the distinction between the sounds in question at the level of words. It would be useful to carry out similar analysis at the level of sentences to distinguish the sounds that are pronounced by the native speakers. But this must be carried out after training students on the perception of sounds at the word level.

\section{References}

Amer, W. (2012) An investigation into the Differences between English and Arabic Consonant and Vowel Sounds: A Contrastive Study with Pedagogical Implications. The Islamic University of Gaza: Palestine. 
Bradlow, A. R., and Pisoni, D. B. (1997). Training Japanese Listeners to Identify English /r/ and /l/: Some Effects of Perceptual Learning on Speech Production. Journal of the Acoustical Society of America. P, 101.

Brown, Adam. (1988). Functional Load and the Teaching of Pronunciation. TESOL Quarterly Vol. 22, No. 4.

Carr. P. (2013). English Phonetics and Phonology: An Introduction. Second Edition. Wilefy-• Blackwell.

Carter,R., \& Nunan, D. (2001) Fundamental problems in Phonetics. Edinburg: Edinburg University Press.

Catford, John C. (1987). Phonetics and the Teaching of Pronunciation: A systemic Description of English Phonology. Brown

Derwin, T., Munro, M. and Wiebe, G. (1998). Evidence in Favor of a Broad Framework for Pronunciation Instruction.

Eimas, P. D. (1975) Developmental Studies in Speech Perception. In COHEN, L. B. and SALAPATEK, P. Infant Perception: From Sensation to Cognition, Vol. 2, Academic Press.

Ladefoged, Peter. (2001) A Course in Phonetics. Fourth Edition. Thomson Learning.

Nasr, R. (1967). The Structure of Arabic From Sound to Sentence. Beirut: Libraire de Liban.

O’Connor, J.D. (1981) Better English Pronunciation. Second Edition. Cambridge University Press.

Permuttler, M. (1989). Intelligility Rating of L2 Speech pre- and post intervention. Perceptual and Motor Skills, 68.

Roach, p. (2000). English Phonetics and Phonology. Third Edition. Cambridge University Press.

Rochet, Bernard L. (1995). Perception and production of L2 speech sounds by adults. In TRANGE, W. Speech perception.

Streeter, L. A. (1976) Language Perception of two-months old infants effects of both innate mechanisms and experience. Nature, 259.

Todd, L. (1987) An Introduction to Linguistics. Harlow: Language Group, UK limited.

Werker, J. F. (1989). Becoming a Native Listener. American Scientist, 77.

Yarmohammadi, L. (1996). A Contrastive Phonological analysis of English and Persian. Shiraz; Sheraz University Press.

Yule, George.( 2006) The Study of Language. Third edition, Camgridge University. 